\title{
From anecdote to EBM
}

\section{INTRODUCTION}

Given an opportunity for an historical introduction cardiac surgeons like to quote Stephen Paget from his 1896 book The Surgery of the Chest:

'Surgery of the heart has probably reached the limits set by Nature to all surgery: no new method, and no new discovery, can overcome the natural difficulties that attend a wound of the heart.' 1

This was in the context of suturing a stab wound of the heart. A century later virtually no structural abnormality of the heart - congenital, acquired or degenerative - was surgically irrepairable. Changed also is the nature of evidence required to justify practice. Paget's teaching, typical of its time, employs descriptions of clinical cases. ${ }^{1}$ The challenge now is to practice 'evidence-based medicine', ${ }^{2}$ but there may be more in the rhetoric rather than the reality.

\section{THE ASCENDANCY OF A CATCH PHRASE}

The phrase evidence-based medicine (EBM) first appeared as an index term in 1992 with two publications. There were six citations in 1993, 12 in 1994 and 10 years later over 3000 in 2004. EBM is based on randomized clinical trials (RCTs) and systematic reviews. ${ }^{3}$ However, there are so few RCTs in surgery that maybe there is more in presentation than reality. Paget based his book on what he had learned from his colleagues and his own personal experience, illustrated by clinical examples. He might well have asked 'Is not what I practice based on evidence?'. The task I have set myself in this essay is to answer this imagined question and to explore what is meant by 'evidence' and how it has been understood by 20th century surgeons.

\section{DOES A SINGLE CASE REPORT CHANGE PRACTICE?}

Can a surgeon expect to convert colleagues by describing a single case? We might consider the first successful closure of an infected persistent ductus arteriosus (PDA) in 1939 as one such. Babies who survived the early months with a PDA

The Thoracic Unit, Guy's Hospital, London, UK

E-mail: Tom.Treasure@ukgateway.net in the first half of the 20th century were very likely to reach adult life; and, although there was nothing that could be done to rectify the anatomy and consequent physiological abnormality, most lived until at least their $50 \mathrm{~s} .{ }^{4}$ There were two children who had operations performed to close the ductus in children in 1937 and 1938, with one surviving. ${ }^{5}$ Stephen Paget's opinion (that the heart was beyond the reach of surgeons) still held sway and this experience with a $50 \%$ death rate would not overturn it. But if the duct became infected it was uniformly fatal, typically with a predictable course over months. In the pre-antibiotic era, infection could not be eradicated and certainly not while the turbulent flow persisted. Oswald Tubbs, working at St Bartholomew's hospital successfully tied an infected duct in a 23-year-old man in $1939.5^{5}$ This operation is seen as a watershed, a point in time when a single event changed practice. In surgical history 'firsts' are cited but does a single case change practice? It must be very rare. Perhaps there are some operations that only have to be done once to prove they should enter practice but more likely these are landmarks of a complex process that built up to and followed the single case.

Paget's book with its many case vignettes appears to be anecdotal teaching based on case reports. This would be to misunderstand what he was doing. His teaching is eclectic based, not only in his own experience but the pooled experience of others. He describes several cases of men injured in the American civil war. Paget can only have been 10 years old so this is a case vignette, illustrative of evidence that is more broadly based than anecdotes of his own experience. This is not stated explicitly, nor is his method transparent but, understood in this way, little has changed in our weekly teaching rounds. A single case is a 'for instance'; it is not the sole evidence for what we teach.

\section{MITRAL VALVOTOMY: A 50-YEAR SAGA}

Surgery for mitral stenosis certainly relied on much more than a single success. The physician Lauder Brunton eloquently set out the problem in $1902 .{ }^{6}$

'Mitral stenosis is not only one of the most distressing forms of cardiac disease, but in its severe forms it resists all treatment by medicine. On looking at the contracted mitral orifice in a severe case of this disease one is impressed by the hopelessness of ever finding a remedy which will enable the auricle to drive the 
blood in a sufficient stream through the small mitral orifice, and the wish unconsciously arises that one could divide the constriction as easily during life as one can after death.'

Brunton was rather harshly rubbished by the Lancet: it was only a theory and he had better do some experiments. Although laboratory studies were set up later to explore the possibility of surgery, none of the animal work reflected the human condition or adequately modelled the surgery to relieve it. Animal evidence did not influence practice in this case.

Then in 1923 in Boston, Massachussetts, Cutler operated on mitral stenosis putting a knife up through the ventricle to cut the valve ${ }^{7}$. In 1925 Henry Souttar performed just the operation that Brunton had proposed. ${ }^{8}$ He put his right index finger through the mitral valve relieving stenosis. The young girl was improved and lived for several years. She was feted and shown off to Royalty. Souttar never did a second operation. Cutler's first patient also survived but a further six patients died within days of surgery and he abandoned his attempts. He summarized the work in a further paper in $1929 .{ }^{9}$ He used the words 'a final report' thus calling a moratorium on the surgery for mitral stenosis.

Conybeare's and Price's textbooks of medicine — which came out in frequent editions throughout the 1930s - at first noted mitral valvotomy in neural tones. They became progressively more opposed to surgical attempts to relieve mitral stenosis, although there was no further surgery since Cutler's self imposed moratorium in 1929. Sir Thomas Lewis in his 1943 edition of Diseases of the Heart wrote:

Surgical attempts to relieve cases of mitral stenosis presenting failure [sic] by cutting the valve have so far failed to give benefit. I think they will continue to fail, not only because the interference is too drastic, but because the attempt is based upon what, what usually at all events, is an erroneous idea, namely that the valve is the chief source of the trouble.

Lewis, the doyen of clinical science, tells the surgeons that not only is surgery too dangerous - it is also misconceived. It was both reckless and illogical. This was strong rhetoric from powerful opposition.

\section{THE EVIDENCE FOR MITRAL VALVOTOMY}

In my analysis of the historical evidence, two things happened that helped overcome this impasse. The first was brought about by war. Dwight Harken (1910-1933) a Boston trained surgeon working in an American Army Hospital in Cirencester operated to remove missiles from in and around the heart and great vessels on 134 soldiers. ${ }^{10}$ that it was at least possible to work within the heart. While Harken used the opportunities provided by warfare, another important move was based on diplomacy-a stratagem uncommon amongst surgeons. At Guy's Russell Brock (1903-1980) was interested in the problems of the heart and great vessels. He knew all the arguments and the strength of the opposition. In 1947 He formed a club for those interested in surgery for heart disease, and those whose interest he needed to capture. He invited his colleagues at Guy's: the physicians, the pathologists, the anaesthetists, the research workers of the Medical Research Council then at Guy's, and the Hospital Superintendent (equivalent to today's Medical Director).

In the USA Harken and another American, Charles Bailey, between them performed a handful of attempted operations on the mitral valve with a run of deaths. But then each had a survivor in June 1948. On Monday 13 September 1948 Brock had two patients with mitral stenosis presented to his associates (Figure 1). Within the week, Brock's first patient was on the operating table. He operated on two more patients with mitral stenosis in the following week. He had seven survivors in his first nine including two American patients operated upon during a visit to Johns Hopkins, in Baltimore. ${ }^{11}$ Brock quickly built up a series of cases with consistent results ${ }^{12}$ and the operation was taken up all over the world.

\section{BUT THERE WAS NO CONTROL GROUP}

Where the natural history of a disease is well known, an intervention that quite clearly changes the course of events will be accepted but do we always know what would have happened if we had not operated? After Brock's success his sage colleague and cardiologist Maurice Campbell (18911973) wrote: 'now that we have to take decisions about when to advise operation for these patients we realise the urgent need of accurate knowledge of the natural history and prognosis'. If the disease is well documented and inevitably fatal in the short term (such as endocarditis on the ductus) or relentlessly progressing in the long term (as in mitral stenosis), a few successes are seen as sufficient to change practice. But these are 'historical controls' and we should be wary of them. I think this is particularly true in cancer surgery. We select patients for surgery and if they have as yet not demonstrated a propensity of the tumour to metastasise. Small wonder that they are more likely to be alive 5 years later than the rest of the population who we turned down for surgery. We rarely have a genuine control group and yet the belief that we do good makes it near impossible to persuade colleagues to run an RCT with a non-operated control group.

In the case of mitral stenosis the more severe and symptomatic cases were operated upon, the natural history 


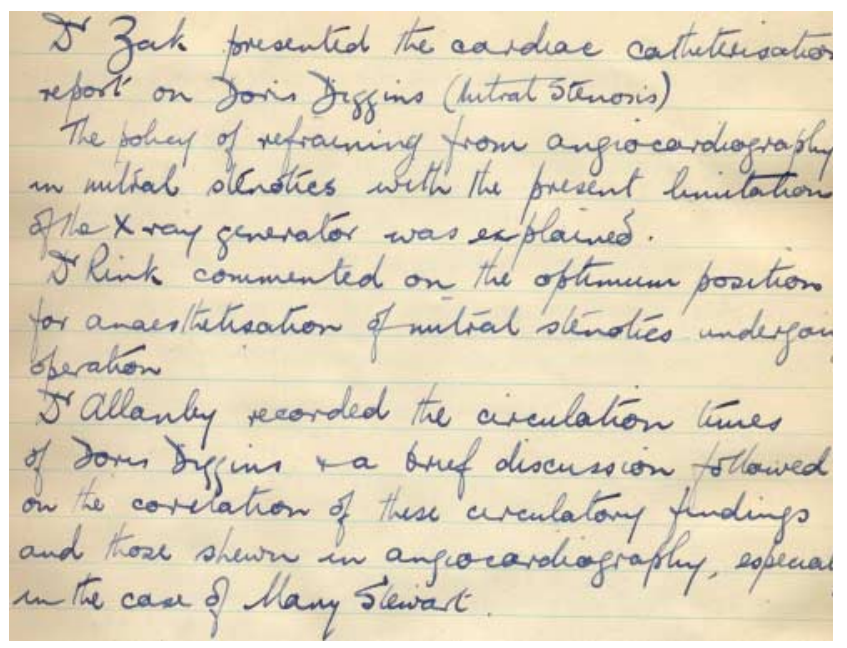

Figure 1 Russell Brock's notes on two patients with mitral stenosis

was very well known; and it was consistently altered in terms of survival and morbidity by valvotomy. Quite soon waiting lists developed.

\section{WHAT DRIVES CHANGE: EVIDENCE OR POPULAR DEMAND?}

Cataract and hip replacement were operations for common debilitating conditions. Once they could be relieved by surgery, the belief in their benefit was such that waiting lists soon developed. In 1995 Yates roundly criticized surgeons for spending time in private practice and neglecting the Health Service in his book Private Eye, Heart and Hip, referring to the waiting list leaders: cataracts, coronaries and hips. On what evidence was the widespread uptake of these operations based? Not randomized trials. It was a knowledge of the natural history of these conditions. They progressed remorselessly over the years and there were no spontaneous remissions. After hip and cataract surgery 'the lame walked and the blind recovered their sight' (Matthew 15;29-31). Coronary artery surgery, which was also impressively effective in relieving the symptom angina, had another dimension: the fear of death while waiting.

The extent to which coronary surgery (and in due course angioplasty) protected survival was to be the subject of RCTs. In the selected cases that could be randomized the effect was relatively small but deaths on the waiting list were much publicised and the burden on the surgeons was considerable. ${ }^{13}$ There is a belief that coronary surgery saves lives which is widespread and seems unshakeable (and which for the record I share). Does angioplasty?

\section{LOGIC AND MECHANISMS VERSUS EMPIRICAL EVIDENCE OF BENEFIT}

In the 1960s medicine was seen as a scientific and logical extension of basic science as explored in the laboratories and in clinical research. There are biological mechanisms that clearly work: insulin lowers blood sugar, heparin stops blood clotting. EBM has shifted the emphasis and talks not in terms of mechanisms but 'outcomes'. The modern health services researcher in the era of EBM asks not whether insulin lowers blood sugar. That is not enough. She asks 'are diabetics on insulin living better and longer lives and are they spared blindness and renal failure?'. Similarly, it is not enough that heparin stops blood clotting. The clinical question is 'does the use of subcutaneous heparin translate into fewer lives lost from pulmonary embolism and fewer legs wrecked by post phlebitic syndrome?'.

Persuasion, conversion and changing practice requires more than the crisp presentation of what the proponents might regard as scientific proof. This brings us a little closerI believe - to understanding what is new about the word 'evidence' as used in the phrase 'evidence-based medicine'.

A generation of doctors in modern scientific medicine was largely spared the problems of counting the cost. But as medicine in general, and surgery in particular, were seen to be effective, and the money in one way or another came out of the nation's resources, the matter of cost containment had to be addressed. ${ }^{14}$

So long as all the physician had to offer the patient was his own time and advice and a few herbs and powders, both medicine and society could comfortably claim that the physician's duty of fidelity was owed solely to the individual patient.

When physicians can, with the stroke of their pens, literally bankrupt the community, the community may no longer be able to tolerate that view of the physician's duty.

So, as I reflect on the way surgeons present evidence for what they do, and how society would harness their enterprise, it appears to me that there is another meaning behind evidence-based medicine. RCTs in many instances are simply not available. EBM is not so much concerned with how we muster the evidence that a treatment is effective; it is that its application should be open to challenged on behalf of a modern society that rightly expects that its money will be spent where it will be most effective. When surgery was limited in its scope and only available to a minority (and it is a moot point whether we consider them the lucky ones or the unlucky ones) evidence of benefit was a matter between surgeons and their immediate colleagues. It is because surgery for many conditions is so effective that we must channel our resources to where it is most effective and away from those where it is futile or unavailing.

The solicitor Bertie Leigh is credited with the statement: 'medicine is too important to be left to doctors'. In this era of NICE guidelines we might expand that and say: 
delivering effective medicine is too costly and complicated for decisions to be left to individual doctors.

Acknowledgments This paper is based on the first Geoffrey Flavell Lecture given at the Society of Apothecaries on 24 May 2005.

\section{REFERENCES}

1 Paget S. The Surgery of the Chest. Bristol: John Wright, 1896

2 Treasure T, Keogh B, Hunt I, Pagano D. The Evidence for Cardiothoracic Surgery. Shrewsbury: TFM, 2005

3 Hill J, Hunt I. Applying evidence based medicine to cardiothoracic surgery. In: Treasure T, Keogh B, Hunt I, Pagano D, eds. The Evidence for Cardiothoracic Surgery. Shrewsbury: TFM, 2005:1-4

4 Kirklin J, Barratt-Boyes B. Cardiac Surgery. New York: John Wiley, 1986

5 Hurt R. The History of Cardiothoracic Surgery from Early Times. Carnforth: Parthenon, 1996
6 Brunton L. Preliminary note on the possibility of treating mitral stenosis by surgical methods. Lancet $1902 ; \mathbf{i}: 352$

7 Cutler E, Levine S. Cardiotomy and valvulotomy for mitral stenosis. Experimental observations and clinical notes concerning an operative case with recovery. Boston Med Surg J 1923;188:1023

8 Souttar HS. The surgical treatment of mitral stenosis. BMJ 1925;ii:603-7

9 Cutler EC, Beck CS. Present status of surgical procedures in chronic valvular disease of the heart; final report of all surgical cases. Arch Surg 1929; 18:402-16

10 Harken DE. Foreign bodies in, and in relation to, the thoracic blood vessels and the heart. Surg Gynecol Obstet 1946;83:117-25

11 Baker C, Brock RC, Campbell M. Valvulotomy for mitral stenosis. Report of six successful cases. BMJ 1950;i:1283-93

12 Baker C, Brock RC, Campbell M, Wood P. Valvotomy for mitral stenosis. A further report, on 100 cases. BMJ 1952;i:1043-55

13 Treasure T. Cardiac Surgery in the Dunkirk spirit. BMJ 1995;311: 1648

14 Brody H, Miller FG. The internal morality of medicine: explication and application to managed care. J Med Philos 1998;28:384 410 